\title{
Aspectos generales de la histología de la glándula salival de las garrapatas con énfasis en Boophilus microplus (Canestrini, 1887) \\ César Mora Hernández ${ }^{*}$
}

Resumen.- El artículo presenta elementos de histología de las glándulas salivales de los artrópodos plagas. Se plantea que si bien las glándulas salivales han sido estudiadas en detalle, aún se sabe poco sobre los mecanismos de transmisión de agentes patógenos, y acerca de las sustancias biológicamente activas que mantienen al "huésped" altamente sensible y posibilitan de esta forma la entrada de otros patógenos no relacionados con vectores. El conocimiento que aportan el estudio de estos procesos permite la elaboración de programas de control epidemiológicos eficientes.

\section{Introducción}

En las garrapatas ixodideas, las glándulas salivales consisten de un par de racimos que se extienden a lo largo de la parte anteroposterior a los lados del idiosoma, formada por una serie de diferentes tipos de alvéolos, fijados a conductos ramificados que se conectan entre sí y desemboca en el aparato bucal (hipostoma). La glándula salival está sujetada por el tejido conectivo y las ramificaciones de las tráqueas.

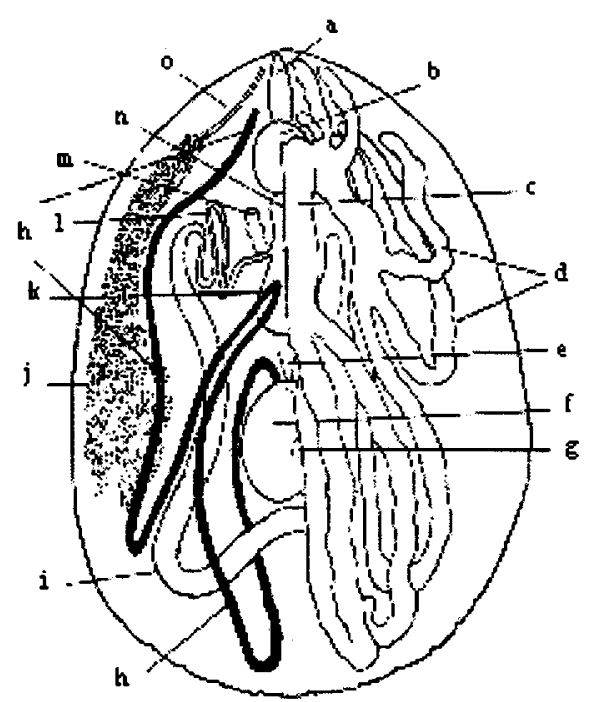

La glándula salival de las garrapatas Argasidae están delimitadas hasta el tercer par de coxas y su dimensión no varía independientemente del nivel de repleción; en las garrapatas Ixodidae particularmente de la subfamilia Amblyomminae, a la cual pertenece $B$. microplus las glándulas salivales son mucho más extensas y van más allá del cuarto par de coxas (ver figural). El tamaño depende del estado fisiológico de la garrapata, siendo más grande en garrapatas pletóricas que en las que no están alimentadas.

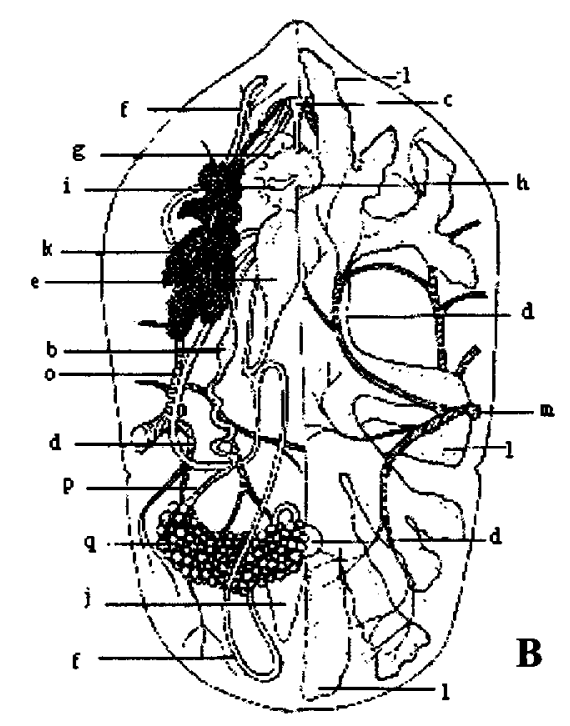

* Profesor de la Facultad de Ciencia y Tecnología del Ambiente - UCA. 
Figura 1. A. Hembra de Hyalomma asiaticum y B. Ornithodorus papillipis diseccionado sobre la superficie dorsal del idiosoma. A a- faringe; bcerebro; c- intestino; d- divertículo medio; e- asa intestinal media; f- saco rectal; g- ano; h- tubo de Malpigii; i- ovario; j- glándula salival; kreceptáculo seminal; 1 - oviducto; $\mathrm{m}$ - glándula accesoria; n- vagina; o- ducto de la glándula salival. B: a- ano; b- ampolla del oviducto; cfaringe; d- intestino; e- útero; f- tubo de Malpigio; g- cerebro; h- esófago; i- glándula accesoria; jsaco rectal; k- glándula salival; l- divertículo intestinal y tronco traqueal; $\mathrm{m}$ - dorsal; nposterior; o- posterior; $\mathrm{p}$ - oviducto; q-ovario.

Las glándulas salivales de las garrapatas ixodideas posiblemente constituyen uno de los más importantes órganos de interés desde el punto de vista médico y veterinario. Ellas desempeñan un papel fundamental en el mecanismo de la alimentación, así como en otras funciones específicas del metabolismo, como es el caso de la toma del vapor de agua del aire, y, en el caso del macho, la relación entre un cierto tipo de secreción de sus glándulas salivales y el acto de la cópula.

Gran parte del tejido lesionado del huésped está asociado a reacciones provocadas por productos biológicamente activos provenientes de la saliva (figura 2), los cuales traumatizan el sistema vascular adyacente al área de fijación. La reacción de respuesta del huésped a estas secreciones salivales y al tipo de componentes en ellas encontrados, han permitido identificar sustancias como cemento, anticoagulantes, enzimas, prostaglandinas y toxinas.

La importancia de las garrapatas como vectores de agentes patógenos radica en las glándulas salivales, las cuales tienen un rol preponderante cuando la garrapata se encuentra en la fase parasitaria, ya que en ese momento, su actividad funcional es intensa; no obstante el papel desempeñado por la glándula salival en el desarrollo del ciclo de los agentes patógenos y la localización de éstos en los diferentes tipos de alvéolos no es bien conocido, así como de sus tipos específicos de células, sin embargo, son muchas las enfermedades causadas por la inoculación de agentes patógenos directamente transmitidos a través de la saliva de estos artrópodos (figura 2).

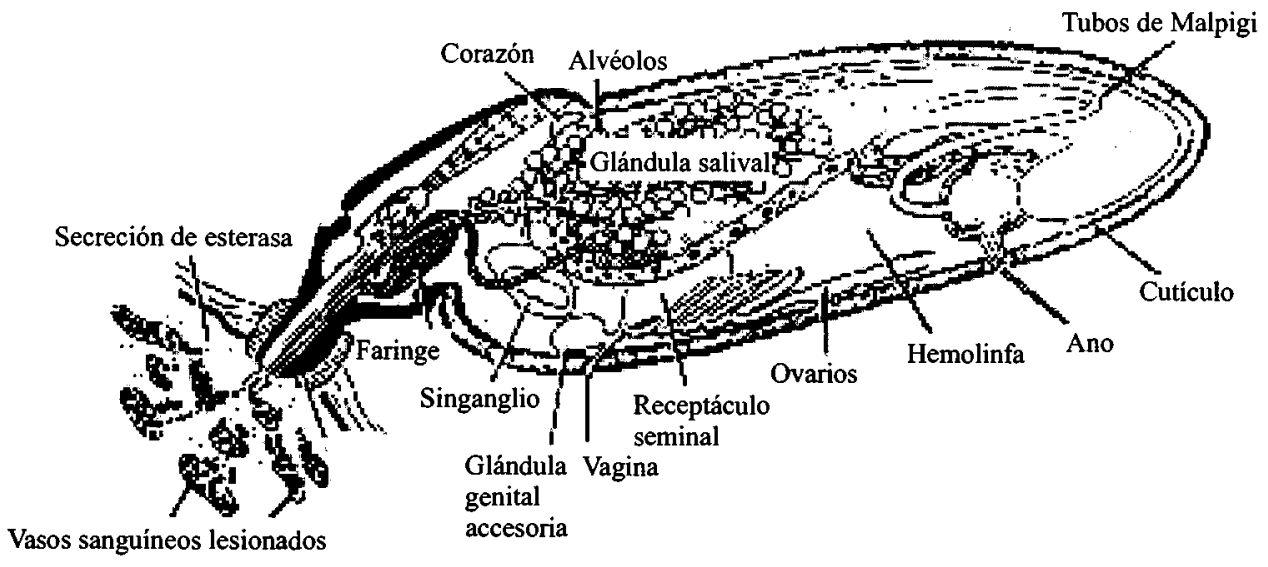

Figura 2. Representación esquemática de la fijación de Boophilus microplus en el huésped, con la consecuente lesión tisular. 


\section{Historia}

Los estudios relacionados con aspectos histológicos de los artrópodos comenzaron motivados por el interés de establecer cultivos celulares de agentes patógenos. Un estudio pionero es el de Goldsmidt (1915), en el cual se utilizó el método de Harrison para cultivo de células de insectos. Esta metodología fue revisada posteriormente por Day y Grace (1959). Así mismo, el primero, segundo y tercer coloquio sobre métodos de cultivos celulares en invertebrados, en Montpellier, Francia (1962); Tremezo y Como (1967), y Smolenice (1971), estimularon grandemente el interés por ésta disciplina (Varna, et al.:1975).

El desarrollo de técnicas de cultivo en órganos y células de garrapata fue un poco más tarde que la de los insectos. Weyer (1952) fue el primero en cultivar tejidos de garrapatas Rhipicephalus bursa; posteriormente Rehacek (1958), estableció cultivos primarios en órganos extirpados de Dermacentor marginatus, y las primeras líneas de células de garrapatas fueron establecidas por Varna (1975) utilizando ninfas entre 8-9 días de ingurgitación de Rhipicephalus appendiculatus.

Sin lugar a dudas, este impulso en el estudio y perfeccionamiento de técnicas de cultivo en tejidos de artrópodos, trajo consigo una potencial explicación en la investigación de transmisión de patógenos, particularmente virus, rikettsias y protozoarios; facilitando de esta manera las posibilidades de estudiar de cerca los requerimientos metabólicos de los mismos así como la relación parásito/huésped; especificidades del huésped y la quimioterapia. Además de eso, estos cultivos in vitro pueden ser usados para producir antígenos y por lo tanto vacunas.

Organos de mosquitos y garrapatas como medio de cultivo, prestan las mejores condiciones para reproducir el ciclo esporogónico de la malaria y para el mantenimiento de cepas de Babesia $s p$. y Theileria $s p$., órganos como las glándulas salivales, ovarios, túbulos de Malpigio y hemócitos que después de continua actividad in vitro, producen secreciones, ovipositan, forman guanina y vacuolas alimenticias respectivamente.

A pesar de que todas las técnicas de cultivos en medios celulares impulsaron un mejor conocimiento de la histología de los artrópodos, es necesario señalar que las investigaciones pioneras de histología y anatomía propiamente dichas son anteriores a estas técnicas, como demuestran los trabajos de Cristophers (1906), Bounet (1906, 1907), ambos citados por Till (1961).

\section{Participación de la glándula salival en la transmisión de agentes patógenos}

El comportamiento de los piroplasmas en la garrapata ha sido una intriga para los investigadores desde inicio del S. $\mathrm{XX}$. Varias tesis intentaron aclarar el ciclo biológico en el huésped invertebrado.

El ciclo de vida de la Babesia sp. en el huésped vertebrado es sencillo; recibe el nombre de "huésped definitivo", y consiste de división binaria en los eritrocitos (Krylov: 1964). 
El ciclo evolutivo de las Babesias sp en las garrapatas es más complicado y consiste en el desarrollo intracelular de varios estadios parasitarios.

El desarrollo del parásito comienza después de la repleción final de la hembra y el desprendimiento de ésta del huésped. El ciclo de desarrollo sexual del protozoario ocurre en las células epiteliales del intestino después de la penetración de los ooquinetos.

La esquizogonia primaria producirá gran cantidad de vermículos, que luego pasan a los hemócitos (células que circulan en la hemolinfa), invadiendo tejidos y órganos. Estos oocistos crecen rápido en los ovarios (Potgelier y Els: 1977).

Las especies de Babesias se transmiten a través de los ovarios hacia las larvas, de éstas a las ninfas y a las hembras jóvenes (neógina); algunos vermículos penetran las células alveolares de la glándula salival donde ocurre una segunda esquizogonia, produciendo partículas infectivas o pequeños merozoítos.

La Babesia bigenima y quizás la $B$. bovis son capaces de no interrumpir su desarrollo en los órganos de la garrapata. Este continuo desarrollo incluye la transmisión transestadial y transovariana (Rieck:1964).

La localización del parásito en las glándulas salivales es específica en las células alveolares tipo I y II (Till: 1961). Estos alvéolos presentan actividad intensa y profundas alteraciones durante el proceso de alimentación de la garrapata; sin embargo, Shortt (1936) señala que la $B$. canis, se puede encontrar en alvéolos no glandulares (tipo I) del Rhipicephalus sanguineus. Similares resultados fueron publicados por Potgieter y Els (1977) para $B$. bigenima en Boophilus decoloratus.

Investigaciones posteriores que enfocan la transmisión de agentes patógenos son los de Stiller (1989), y están relacionados con la detección de colonias de Anaplasma marginale en glándulas salivales de varias especies de Dermacentor, en diferentes estadios de desarrollo. En este estudio se observó que las colonias de Anaplasma marginale inicialmente se establecen en el intestino de la garrapata, y en las células acinares de las glándulas salivales un poco después. Se observó que, aparentemente, las hembras pletóricas sometidas a diferentes temperaturas estimulan el desarrollo de colonias de $A$. Marginale en las células acinares del tipo II y III.

Kokan et. al. (1988), observaron que en las células acinares de las glándulas salivales el $A$. marginale se transforma en formas infectantes; no obstante, en algunas investigaciones posteriores de la misma autora (Kokan: 1990) se inoculó becerros esplenectomizados con colonias de $A$. marginale, provenientes del intestino de ninfas del género Dermacentor, en los cuales la enfermedad evolucionó clínicamente.

Rieck (1964), estudió el ciclo de la $B$. bigemina en el $B$. microplus. Según este investigador, la evidencia de transmisión de $B$. bigemina a los huéspedes fue confirmada hasta 8-10 días después de la fijación de las larvas, debido a que el desarrollo de la glándula salival se da 
después de la écdesis de larva a ninfa. Después de la muda fueron observadas en las células de la glándula formas vermiculares, similares a las localizadas en la hemolinfa. En hembras pletóricas o durante la postura, no fueron encontradas glándulas salivales infectadas.

Potgieter y Els (1977) hicieron algunas observaciones valiéndose de microscopía óptica y electrónica de los merozoítos de $B$. bovis en larvas de B. Microplus. Los resultados de la microscopía óptica encontraron dos tipos de merozoítos de $B$. bovis en las glándulas salivales a las 72 horas de haberse alimentado.

Los citados autores Potgieter y Els (1977) usaron larvas de una colonia de $B$. decoloratus infectadas con $B$. bigenima para infectar un bovino esplenectomizado. Los especímenes fueron manualmente desprendidos a intervalos de 24 horas después de la infestación larval y procesados para observación en microscopía óptica y electrónica. Estos investigadores concluyeron que la esquizogonia primaria sucedió en los tres estadios del ciclo del huésped en forma continua. Los esquizontes primarios y los grandes merozoítos o vermículos, fueron observados en el epitelio intestinal, hemócitos, músculos y células peritraqueales. La esquizogonia secundaria que forma merozoítos (formas infectivas) ocurrió principalmente en la glándula salival.

Consideraciones generales sobre la glándula salival de las garrapatas

Kaufman y Phillips (1973) destacaron la importancia de la glándula salival en la pérdida de agua en Dermacentor andersoni, utilizando hembras adultas, observaron que del total del alimento consumido, aproximadamente el $80 \%$ es excretado. Del total de agua eliminado, $75 \%$ fue por salivación, menos de $3 \%$ por evaporación del tegumento y espiráculos, y menor cantidad por la abertura anal.

Obenchai y Oliver (1976) describieron el sistema nervioso periférico del Amblyomma tuberculatum y Argas radiatus. Entre otros nervios constataron que las glándulas salivales son enervadas por cuatro pares de nervios. El primero par sale del nervio pedipalpal, el segundo y el tercero de los plexus simpáticos laterales y el cuarto, de los nervios paraespiculares.

Kaufman y Harris (1983), estudiaron parte del sistema nervioso de Amblyomma haebraeum determinando reflejos a nivel de la glándula salival, para inhibir o activar la secreción.

Según Balashov (1965) el acto de la salivación es alternado con la succión. Por otro lado, identificó dos tipos de saliva: la primera de aspecto blanco lechosa, producida cuando penetra al huésped; el segundo tipo es más abundante y transparente, se presenta cuando la garrapata está completamente fijada.

Según Kaufman (1973), la secreción de las células granulares de los alvéolos tipos II y III forman cemento con el cual la garrapata se fija a las piezas bucales en la piel del huésped.

Binnington y Kemp (1980) demostra- 
ron con extractos de las glándulas salivales de Argas persicus, Ixodes holocyclus, Dermacentor cinicus, Ornithodorus moubata e Ixodes ricinus que hay propiedades anticoagulantes comprodas.

Goodrich y Murray (1978) desarrollaron metodologías para determinar los factores que influencian la toxicidad de los extractos de las glándulas salivales de Ixodes holociclus, según ellos, la cantidad de toxina aumentó rápidamente a partir del tercer día de haberse alimentado.

Bordeau (1982) refirió que entre las enzimas evidentes en las secreciones salivales de las garrapatas se destacan las fosfatasas, esterasas y polifenoloxidasas.

Higgs et. al. (1976) demostraron la presencia de prostaglandina en el tejido de la glándula salival y en el homogenizado de larvas.

Krolak et. al. (1983) examinaron la localización de la adenosina monofosfato cíclica en las glándulas salivales de las hembras de Amblyomma americanum alimentados y en ayuno.

Brossard (1976) constató por inmunoflourescencia indirecta, que existe paralelo entre las infestaciones y la evolución de anticuerpos anti-saliva de $B$. Microplus.

\section{Morfología de la glándula salival}

Till (1961), en un estudio detallado de la anatomía e histología de la garrapata Rhipicephalus appendiculatus, describió la glándula salival, la cual consiste de un par de masas glandulares, que ocupan la porción lateral de la cavidad del cuerpo. En garrapatas sin alimentarse se extienden posteriormente hasta los espiráculos y son usualmente de mayor tamaño en las hembras que en los machos. Los ductos principales se abren en los ángulos posteriores laterales de la cavidad bucal extendiéndose hacia la parte posterior y ventro lateral a las quelíceras. Esos conductos reciben los racimos secundarios aproximadamente en la mitad de la extensión de la glándula, dividiéndose en racimos de diámetros idénticos. En general la morfología es similar en ambos sexos.

\section{Histología de la glándula salival de la garrapata del género Boophilus.}

Megaw, citado por Sauer (1977) relató haber observado en las glándulas salivales de $B$. microplus hembras, tres tipos de alvéolos (figura 3). Un alvéolo tipo I confinado en la región anterior de la glándula conteniendo células piramidales con membrana basal extensamente doblada; alvéolo tipo II conteniendo tres diferentes tipos de células gránulosecretoras "a", "b" y "c" y alvéolo tipo III con dos tipos de células granulares, "d" y "e". Pequeños cambios fueron observados en el alvéolo tipo I durante la alimentación, por eso es que intensas modificaciones fueron observadas en los alvéolos tipos II y III. Los gránulos de las células "a", "d" y "e" fueron secretadas durante los estadios iniciales de alimentación, en el tiempo correspondiente a la secreción del cemento. Las células "b" y "c" fueron activas en todo el proceso de la alimentación. 


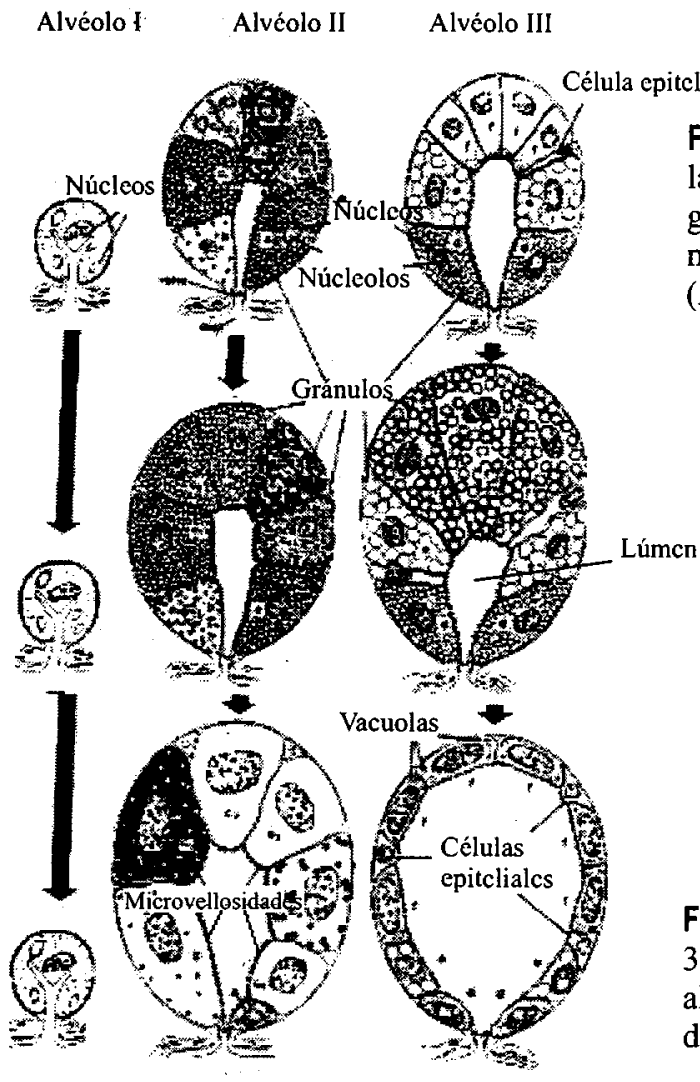

Binnington (1978) utilizó B. microplus macho adulto sin alimentarse, siguiendo la misma metodología que las hembras y estudió diferentes tiempos de alimentación, observando que los alvéolos tipo II en la hembra contenían de 14 a 15 células granulares de seis tipos: "a", "b", "c,", "c ", "c,", y " $\mathrm{c}_{4}$ " además de células intersticiales epiteliales, todas en el contorno de un lumen central se abren por una válvula cutícular hacia un tubo lobular. Todas las células contenían gránulos en adultos sin alimentarse, pero el número de gránulos en la célula " $\mathrm{c}_{2}$ " aumentó notablemente después de 12-24 horas de fijación. El alvéolo tipo III en las hembras, contenía de 16 - 17 células de tres tipos "d","e" e "f".
Figura 3. Esquema que representa la relación entre la producción de cemento, el desarrollo de la glándula salival de $B$. microplus y los cambios morfológicos que ocurren en la piel del huésped (Adaptado de Binnington, 1978).

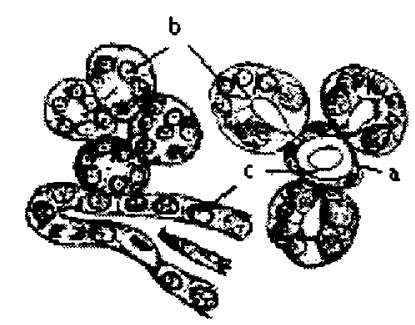

Figura 4. A-B Glándula salival de B. microplus a los 3 y 10 días respectivamente después de haberse alimentado. a- línea cutícular; b- alvéolo secretor; cducto eferente.

De igual manera en las células "d" $y . " e "$ se observaron en forma de paquetes con gránulos en el ejemplar adulto sin alimentarse y perdían la mayoría de sus gránulos después de 72 horas de haberse alimentado (figuras 4, 5 y 6 ).

Las células " $\mathrm{f}$ " fueron más numerosas que las "d" y "e" ocupando el fondo del alvéolo. En el macho la célula "f" fue inactiva en todos los estadios examinados, no existiendo ningún cambio evidente en las células. En los machos, existe un alvéolo adicional, el tipo IV conectado vía conducto lobular principal; son constituidos por las células "g". Ninguna diferencia fue encontrada entre las glándulas salivales de machos vírgenes y no vírgenes. 
Dato de interés es el que se refiere al incremento de la masa glandular durante la alimentación de la garrapata en su proceso de reducción posterior (esto es para las garrapatas del género Argasidae) o en la degeneración tisular después de completar su repleción de sangre (hecho que ocurre en las garrapatas del género Ixodidae). Lindsay (1987) destaca que tal fenómeno se debe a la acción de sustancias esteroides sobre el tejido glandular (figura 6).

\section{Conclusiones}

Los diferentes investigadores citados en la presente revisión, concuerdan en que la estructura histológica de la glándula salival no tiene, según las diferentes especies estudiadas, variación signi- ficativa para ambos sexos; en contraste, las diferencias son evidentes y mayores de acuerdo al grado de alimentación o de ayuno.

La reducción o degeneración de la glándula salival es más acelerada en las hembras porque estas se alimentan continuamente, no así en los machos que se alimentan de forma alternada para buscar a la hembra (Kaufman: 1988).

El conocimiento histológico de la glándula salival ha servido para comprender mejor la fisiología y genética de las garrapatas y utilizarlos en programas de control más racionales y modernos, como es la inmunización contra las garrapatas (Nyindo et. al.: 1989, Musoke E: 1990).
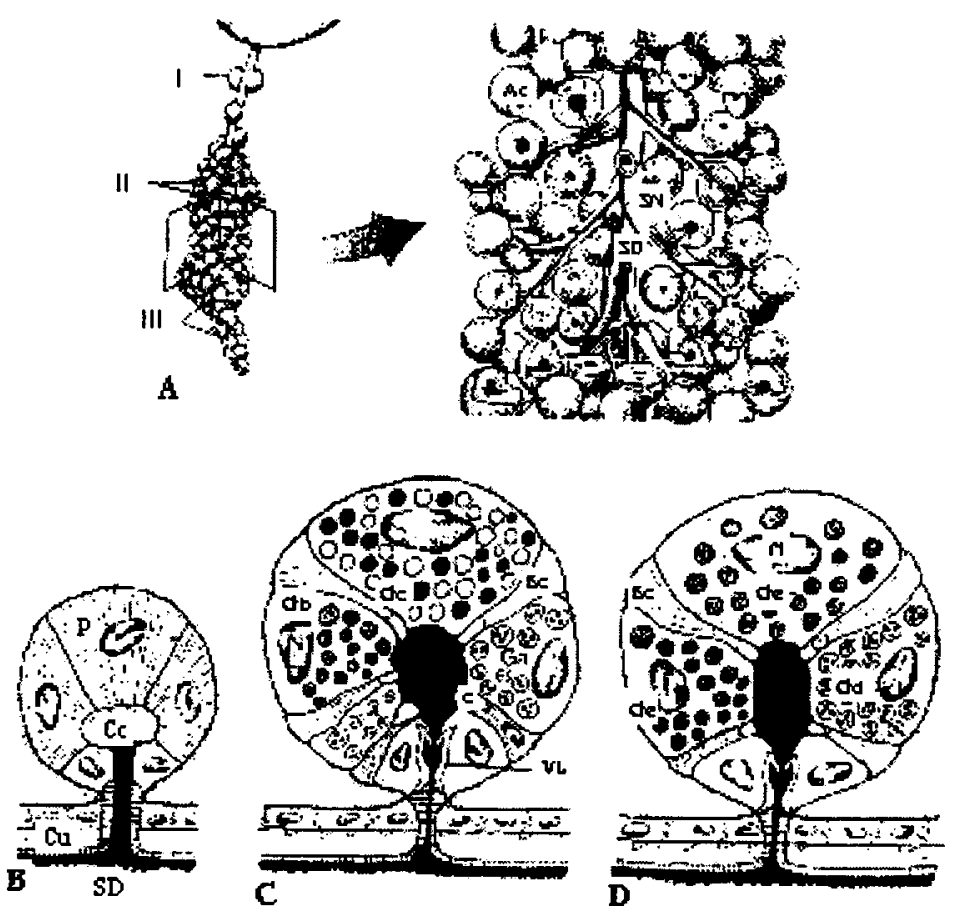

Figura 5. Esquema de glándula salival de B. microplus en ayuno. A- Distribución de los diferentes tipos de alvéolos en la glándula salival. Ac- nervios salivales; SD- sistema de ductos; B-alvéolo tipo I con células piramidales; $\mathrm{C}$ y D-alvéolos tipo II y III. 


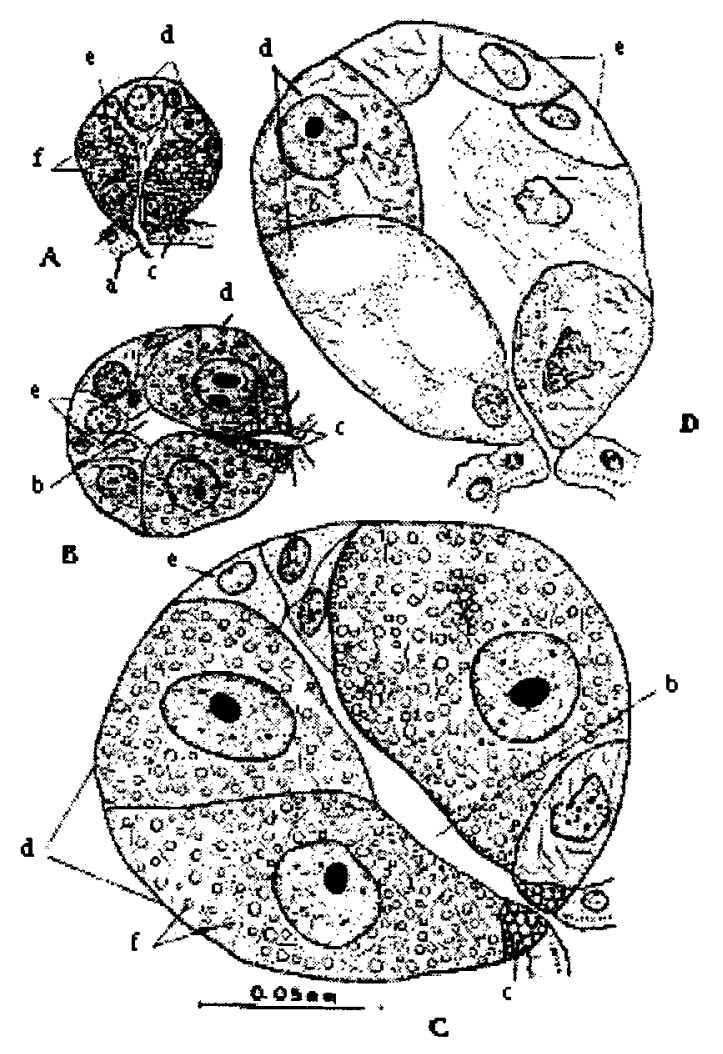

Figura 6. (A- D)- Esquema de alvéolos de glándula salival de hembras de garrapatas Ixodideas, presentando alvéolos secretores tipoII, A- hembra en ayuno; B y C- cinco después de fijadas en el huésped; $D$ - después de alcanzar su repleción y desprenderse del huésped. a- ducto mural; b- cavidad intra alveolar; c- células tipo "a"; d-Células tipo "b"; e- células tipo "c"; f- vacuolas secretoras.

\section{Bibliografía}

1. BALASHOV, Y.S. (1965). "Mechanism of salivation and the morphologic histochemical peculiarities of the salivary glands in ixodid ticks". Entomol. Res., 44:785-802

2. BINNINGTON, K.C. (1978). "Sequential changes in salivary gland structure during attachment and feeding of the cattle tick B. microplus" Int. J. Parasitol. 8:97-115

3. BINNINGTON, K.C. \& KEMP, D.H. (1980). "Role of tick salivary gland in feeding and disease Transmission".Adv.Parasitol., 18:315-333.

4. BROSSARD, M. (1976). "Relations immunologiques entre bovins et tiques, plus particuliérement entre bovins et B. microplu". Acta Trop. XXXIII, I, 15-36

5. BOURDEAU, P. (1982). "La lésion de fixationi des tiques Ixodoidea. Ses modalites et ses conséquences". Rec. Méd. vet., 158(4):383-95.

6. DAY, M.F. y GRACE, T.D.C. (1959)." Culture of insects tissues". Ann. Rev. Entomol. 4: 17-38

7. GOODRICH, B.S. y MURRAY, M.D. (1978). "Factors influencing the toxicity of salivary gland extracts of Ixodes holocyclus". Int. J. Parasitol., 8:313-320

8. HIGGS, G.A., VANE, J.R., HART, R.J.,POTTER, C. \& WILSON, R.G. (1976). "Prostaglandins in the saliva of the cattle tick B. microplus". Bull. Entomol. Res., 66: 665-670.

9. KAUFMAN, W.R. (1988). "The effects of steroids and Azadirachtin on the salivary gland and ovary in ixodid ticks". J. Insect. Physiol., 34 (7):721-723.

10. KAUFMAN, W.R. \& PHILLIPS, J.E. (1973). "Ion and water balance in the ixodid tick, $D$. andersoni. I. Routes of ion and water excretion". J. Exp. Biol.,58:523-536.

11. KAUFMAN, W.R. \& HARRIS, R.A. 1983. "Neural pathways mediating salivary fluid Secretionin the ixodid tick A. Haebraeum". Can. J. of Zool., 61(9):1976-1980. 
12. KOCAN, K.M., WICKWIRE, B., EWING, S.A., HAIR, J.A. \& BARRON, S.J. (1988). "Preliminary studies of the development of A. marginale in salivary glands of adult feeding D. andersoni tick". Am.J. Vet. Res., 49(7):1010-1013.

13. KOKAN, K.M., EDWARDS, W., EWING, S.A., HAIR, J.N., BARRON, S.J. (1989). "Detection of colonies of A. marginale. in salivary glands of three Dermacentor spp. infected as nymphs or adults" Am. J. Vet. Res., 50(8):1381-1385.

14. KOKAN, K.M., YELLIN, T.N., CLAYPOOL, P.L., BARRON, S.J., EWING, S.A. \& HAIR, J.A. (1990). "Development and infectivity of A, marginale. In D. andersoni nymphs". Am.J. Vet. Res., 51(8): 1292-1294.

15. KRILOV, M.V. \& KRILOVA, N.P. (1967). "The ability of Nuttalia tadzhiskistanica to invade ticks depending of the parasitism rats in the vertebrate host". Parazitologiya, 1:329-332.

16.KROLAK, J.M., OWNLY, C.L., BARKER, D.M. \& SAUER, J.R. (1983). "Immunohistochemical localization of adenosine 3'-5'-cyclic monophosphate in female ixodid tick $A$, americanum salivary glands". J. Parasitol., 69(1):152-157.

17. LINDSAY, P.J. \& KAUFMAN, W.R. (1987). "The efficacy of Azadirachtin of putative ecdysteroid-sensitive systems in the ixodid tick A. Americanum". J. Insect. Physiol., 34 (6):439 442 .

18. NYINDO, M., ESSUSMAN, S. \& DHADINLLA, T.S. (1989). "Immunization against ticks: use of salivary gland antigens and infestations with Rhipicephalus appendiculatus in Rabbits". J. Med. Entomol., 26(5):430-434.

19. MUSOKE, A.J. \& NENE, V. (1990). "Development of recombinant antigen Vaccines for the control of theileriosis". Parasitologia, 32:73-85.

20. OBENCHAIN, F.D. \& OLIVER, J.H. (1976)." Peripheral nervous system of the ticks, Amblyomma tuberculatum and Argas radiatus". J. Parasitologia, 62 (95):811-817.

21. OBENCHAIN FREDERICK \& GALUN RACHEL. (Editors) (1982). Physiology of ticks. Current themes in tropical Science. Pergamon Press, $509 \mathrm{pp}$.

22. POTGIETER, F.T. \& ELS, H.J. (1977). "Light and electron microscopic observations on the development of small merozoites of Babesia bovis in Boophilus microplus larval". J. Vet. Res., 43 (3): 123-128.

23. RENACEK, J. \& BRAZINA, R. (1958). "Propagation of Coxiella burneti in tick tissues culture". Acta Virol., 8:380.

24. RIECK, R.F. (1964). "The life cycle of the Babesia bigemina in the tick vector Boophilus microplus". Aust. Agr. Res., 17:247-254.

25. SAUER, J.R. (1977). "Acarine salivary glands physiological relationships". J. Med. Entomol., $14(1): 1-19$.

26. STILLER, D., KOCAN, K.M., EDWARDS, W., EWING, S.A., HAIR, J.A. \& BARRON, S.J. (1989). "Detection of colonies of Anaplasma miarginale in salivary glands of three Dermacentor spp. infected as nymphs or adults". Am. J. Vet. Res., 51 (8):129-136.

27. TILL, W.M. (1961).A contribution to the anatomy and histology of the brown ear tick Rhipicephalus appendiculatus, Neumann. South African Inst. for Med. Res., Johannesburg. 145 pp.

28. VARNA, M.G.R., PUDNEY, M. \& LEAKE, C.J. (1975). "The establishment of three cell lines from the tick Rhipicephalus appendiculatus and their infection with, some arboviruses". J. Med. Entomol., 11:698-706.

29. WEYER, E. (1952). "Experimental explanation of lice related to the culture of Rikettsia". Zentrlbl. Bacteriol. (orig. I) Abt. 159:13-22 